\title{
Incidence and predictors of regimen-modification from first-line antiretroviral therapy in Thailand: a cohort study
}

Naho Tsuchiya ${ }^{1,2}$, Panita Pathipvanich ${ }^{3}$, Nuanjun Wichukchinda ${ }^{4}$, Archawin Rojanawiwat ${ }^{4}$, Wattana Auwanit ${ }^{4}$, Koya Ariyoshi ${ }^{1,2^{*}}$ and Pathom Sawanpanyalert ${ }^{5}$

\begin{abstract}
Background: Antiretroviral therapy markedly reduced mortality in HIV-infected individuals. However, in the previous studies, up to 50\% of patients are compelled to modify their regimen in middle and low-income countries where salvage drug is still limited. This cohort study aimed to investigate the incidence and predictors of regimen modification from the first-line antiretroviral regimen in northern Thailand.

Methods: All HIV-infected patients starting antiretroviral therapy (ART) with generic drug (GPOvir®; stavudine, lamivudine and nevirapine) at a governmental hospital in northern Thailand from 2002 to 2007 were recruited. Baseline characteristics and detailed information of regimen modification until the end of 2010 were ascertained from cohort database and medical charts. As a potential genetic predictor of regimen modification, HLA B allele was determined by bead-based array hybridization (WAKFlow ${ }^{\circledR}$ HLA typing kit). We investigated predictors of the regimen modification using Cox's proportional hazard models.
\end{abstract}

Results: Of 979 patients, 914 were eligible for the analysis. The observed events of regimen modification was 377, corresponding to an incidence 13.8/100 person-year-observation (95\% Cl:12.5-15.3) over 2,728 person years (PY) follow up. The main reasons for regimen modification were adverse effects (73.5\%), especially lipodystrophy (63.2\%) followed by rash (17.7\%). Sixty three patients (17.1\%) changed the regimen due to treatment failure. $2 \%$ and $19 \%$ of patients had HLA-B*35:05 and B*4001, respectively. HLA-B*35:05 was independently associated with rash-related regimen modification (aHR 7.73, 95\% Cl:3.16-18.9) while female gender was associated with lipodystrophy (aHR 2.11, 95\% Cl:1.51-2.95). Female gender (aHR 0.54, 95\% Cl: 0.30-0.96), elder age (aHR 0.56, 95\% Cl: 0.32-0.99) and having HLA-B*40:01 (aHR 0.29, 95\% Cl: 0.10-0.82) were protective for treatment failure related modification.

Conclusion: HLA-B*35:05 and female gender were strong predictors of regimen modification due to rash and lipodystrophy, respectively. Female gender, elder age, and having HLA-B*40:01 had protective effects on treatment failure-related regimen modification. This study provides further information of regimen modification for future tailored ART in Asia.

Keywords: Antiretroviral therapy, Regimen modification, Predictor, Thailand, Resource limited settings, Adverse effects

\footnotetext{
* Correspondence: kari@nagasaki-u.ac.jp

${ }^{1}$ Department of Clinical Medicine, Institute of Tropical Medicine, Nagasaki

University, 1-12-4, Sakamoto, Nagasaki 852-8523, Japan

${ }^{2}$ Global COE program, Nagasaki University, 1-12-4, Sakamoto, Nagasaki

852-8523, Japan

Full list of author information is available at the end of the article
} 


\section{Background}

Antiretroviral therapy (ART) has markedly reduced AIDSrelated mortality and morbidity [1]. The combination of stavudine (d4T), lamivudine (3TC) and nevirapine (NVP) has been one of the most common first-line ART regimens in resource limited settings. Even after stavudine for newly treated patients is being phased out according to WHO's recommendation, this combination is still widely used in these settings. In Thailand, the fixed-dose generic combination antiretroviral drug, GPOvir ${ }^{\circ}$ (d4T,3TC and NVP), has been universally available since 2002 [2]. The efficacy of GPOvir and survival benefit has been demonstrated [2,3]. Despite of the increased access to ART, adverse effects compelled patients to discontinue or modify the regimen more frequently than ART treatment failure. Previous studies showed that up to $50 \%$ of patients modified their first-line regimen due to adverse effects [4-9]. A multicenter study in Asia demonstrated that the rate of regimen modification from the combination of $\mathrm{d} 4 \mathrm{~T} / 3 \mathrm{TC} /$ NVP until October 2004 was 22.3/100 person-yearobservation (PYO) and 62.6\% were due to adverse effects among patients in Asian and Pacific countries [5]. Major adverse effect resulted in the regimen modification was lipodystrophy, followed by hepatotoxicity and rash in the study. Other studies in resource-limited settings showed the consistent results [6-8].

Several demographic, clinical and genetic factors associated with adverse effects have been identified. Female with a higher CD4 cell count, better clinical status and a higher BMI at ART initiation were associated with NVP-induced rash in Thai patients [10]. Another study showed that hepatitis co-infection and elevated alanine aminotransferase increased the risk of hepatotoxicity due to NVP containing ART [11]. In terms of pharmacogenetic factors, HLA-B*57:01 is known to be a strong predictor of hypersensitivity to abacavir [12] and screening has been widely implemented in western countries. In Asia, where the frequency of $B * 57: 01$ was low, associations between HLA$B * 40: 01$ and lipodystrophy, and HLA-B*35:05 and rash were reported in small case-control studies [13,14]. Regimen modification due to these adverse-effects with/without these specific alleles was not evaluated as an outcome in their study.

To our knowledge, only few observational studies comprehensively investigated predictors of ART regimen modification in clinical settings in low- and middle-income countries $[6,7,15]$. This study, therefore, aimed to examine the more recent incidence and predictors of regimen modification of the first-line ART in northern Thailand.

\section{Methods}

\section{Study site and population}

We conducted this study as a sub-study of our previously conducted observational cohort of HIV-infected patients at the HIV centre of a government referral hospital situated in the centre of Lampang province in northern Thailand. Detailed information on the original cohort is presented elsewhere [16]. Participants were all adult (aged $>18$ years) HIV-infected individuals attending the HIV clinic with given written consent. Any ARTnaïve participants in the original cohort who initiated ART with GPOvir (d4T $30 \mathrm{mg}+3 \mathrm{TC} 150 \mathrm{mg}+\mathrm{NVP}$ $200 \mathrm{mg}$ ) until 31 December 2007 were incorporated into this ART patient cohort. Those who experienced ART other than prevention for mother to child transmission (PMTCT) prior to first visit at the HIV centre were excluded. All participants were requested to visit the clinic at least once every 3 months and were followed up until the end of 2010.

\section{Data collection}

The baseline was the time of initiating antiretroviral therapy. The outcome of interest was the first regimen modification from the first-line antiretroviral therapy for any reasons. In this study, regimen modification was defined as any changes in antiretroviral drugs (including single substitutions). Demographic and clinical data at the baseline were obtained from medical records and face-to-face interviews based upon a structured questionnaire. Regimen modification date, one main reason for the regimen modification, and the regimen after modification were ascertained by the cohort database or medical charts. Decision of regimen modification and diagnosis of each adverse effect were made based on the national and international guidelines throughout the observation period. Reasons for regimen modification were coded as follows: adverse effects, treatment failure, drug resistance, pregnancy and treatment for tuberculosis and others. Covariates of interest were: gender, age, mode of HIV transmission, clinical status and CD4 cell count at the baseline, and Human leukocyte antigen (HLA) - B allele.

\section{Human leukocyte antigen (HLA) genotyping}

Blood samples for genotyping were obtained at the baseline. Genomic DNA was extracted from buffy coat using the QIAmp DNA blood Mini Kit (Qiagen, Hilden, Germany) and 4-digit HLA class I typing for B loci was undertaken by bead-based array hybridization (WAKFlow ${ }^{\circ}$ HLA typing kit, Wakunaga Pharmaceutical Co., Ltd., Hiroshima, Japan) according to manufacturer's instructions at a commercial laboratory (Kyoto HLA Laboratory, Kyoto, Japan).

\section{Decision of regimen modification}

Throughout the observation period, we made a decision of regimen modification following the $\mathrm{WHO}$ guideline which was issued in 2002 [17]. According to the criteria, 
adverse effect-related regimen modification was considered when; rash with systemic symptoms such as fever, severe rash with mucosal lesions of urticaria, or StevensJohnson syndrome or toxic epidermal necrolysis, severe neuropathy, more than 5 times increase of the normal limit in liver enzyme, any type of lactic acidosis. In this criteria, regimen modification due to lipodystrophy was not recommended because of the limited salvage regimen. In the Thai national guideline issued in 2008 and the modified one issued in 2010, it was stated that "Early switching of causative ARV may avoid irreversible lipodystrophy.", but the timing of regimen modification was not clearly defined $[18,19]$. The Thai national guideline issued in 2008 which was used during the study period defined criteria for virological failure as HIV viral load (VL) $>1000$ copies/ml after 6 months of receiving ART with good adherence, or a rebound of VL to $>1000$ copies $/ \mathrm{ml}$ in any duration after achieving $\mathrm{VL}<50$ copies $/ \mathrm{ml}$ [18]. Criteria for immunological failure include: CD4 + T-cell count increases $<50$ cells $/ \mathrm{mm} 3$ after a year of ART; absolute CD $4+\mathrm{T}$-cell count decreases $>30 \%$ or percent $\mathrm{CD} 4$ decreases $>3 \%$ from the highest level previously gained; CD $4+\mathrm{T}$-cell count decreases to the level lower than pre-ART level [18]. Clinical failure is defined as clinical relapse of prior OI or occurrence of a new OI [18]. However, practically, annual VL testing has not been fully implemented until late 2000's. Thus our definition of treatment failure was mainly by immunological and clinical failure in this study. Immunological failure and clinical failure are given less importance in the current national guideline because of low sensitivity and specificity, but still used in other resource-limited countries [19].

This study was approved by the Thai Government Ethics Committee in December 1999 and December 2005.

\section{Statistical analysis}

The primary endpoint was the time to the first regimen modification after starting ART with GPOvir ${ }^{\circ}$. All patients were censored at the last visit date before data collection if no event of regimen modification or death had occurred; the last censored date was 31 December 2010. In case of death, moving, and changing to other hospitals, the data were censored at that time point as well. After descriptive summaries, we calculated incidence rates of regimen modification with $95 \%$ confidence intervals (CI). Kaplan-Meier estimates for the probability of survival without regimen modification was performed. After identifying the reasons for regimen modification, Cox's proportional hazard models were fitted in order to identify the factors associated with regimen modification for different reasons. In the multivariable models, we put variables with p-value under 0.05 in the univariable analysis and covariates of interest. All statistical analyses were performed using STATA version 12.0 (Stata corp, College station, Texas).

\section{Results}

\section{Baseline characteristics of study participants}

Between 1 August 2002 and 31 December 2007, 979 ART-naive HIV-infected patients started ART with GPOvir ${ }^{\circ}$ at the HIV clinic in Lampang hospital. Of these, 49 patients who actually did not start GPOvir and 16 patients who did not meet the criteria were excluded. Subsequently, 914 participants were included in the analyses (Figure 1). Table 1 shows baseline characteristics at the initiation of ART and frequency of HLA-B*35:05 and $B^{*} 40: 01$. Almost half of the participants were male and the majority of patients got infected with HIV via heterosexual transmission. At the initiation of ART, around $60 \%$ of patients had already had AIDS defined illness and the median CD4 cell count was as low as 50 cells/ $\mathrm{ml}$ (Interquartile range, IQR 17-118). Out of 908 participants whose data on HLA-B allele was available, 18 (2.0\%) had HLA-B*35:05 allele and 168 (18.5\%) had $B^{*}$ 40:01 allele. Frequency of other HLA alleles was shown in Additional file 1: Table S1.

\section{Regimen modifications and reasons}

The median follow up from ART initiation was 89.8 months. The observed events of regimen modification were 377 over 2,728 person years (PY) of follow up, corresponding to the incidence rate of $13.8 / 100 \mathrm{PYO}$ (95\% CI 12.5-15.3).

Table 2 summarizes the reasons for the regimen modification and time from ART initiation. The most common reason for modification was adverse effects of GPOvir $^{\circ}$ (73.5\%), followed by treatment failure (16.7\%), for treatment of tuberculosis (TB) (4.2\%), and pregnancy (2.7\%). For the patients who developed TB or became pregnant, GPOvir ${ }^{\circ}$ was changed to the combination of $\mathrm{d} 4 \mathrm{~T} / 3 \mathrm{TC} / \mathrm{Efavirenz}(\mathrm{EFV})$ and zidovudine/3TC/NVP, respectively. Detailed distribution of adverse effects resulting in regimen modification is also shown with days to regimen modification. Lipodystrophy (63.2\%), rash (17.7\%),

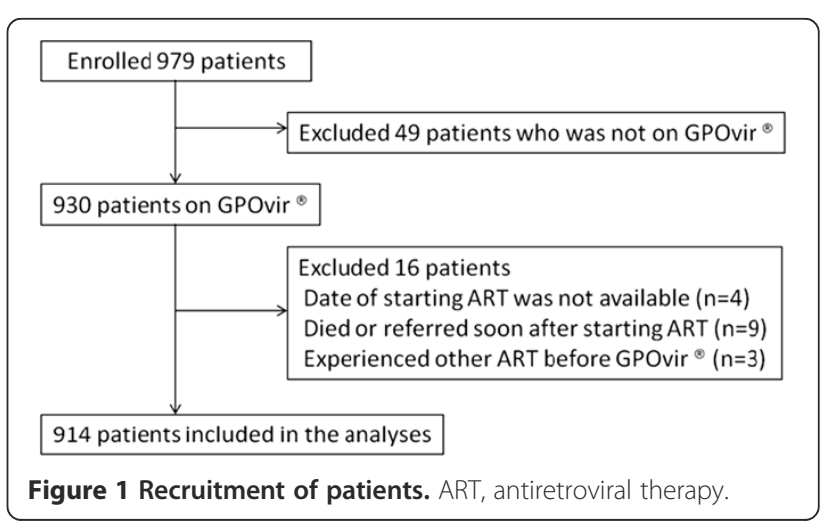




\begin{tabular}{|c|c|}
\hline \multicolumn{2}{|l|}{ Gender } \\
\hline Male (Number, \%) & $461(50.4)$ \\
\hline Age (Median, IQRª & $34.6(30.6-39.6)$ \\
\hline \multicolumn{2}{|l|}{ Mode of transmission (Number, \%) } \\
\hline Heterosexual & $848(92.8)$ \\
\hline Homosexual & $15(1.6)$ \\
\hline$I D U^{b}$ & $29(3.2)$ \\
\hline Others/unknown & $22(2.4)$ \\
\hline \multicolumn{2}{|l|}{ Clinical symptoms (Number, \%) } \\
\hline Asymptomatic & $124(13.6)$ \\
\hline Symptomatic & $217(23.7)$ \\
\hline AIDS & $549(60.1)$ \\
\hline Unknown & $24(2.6)$ \\
\hline CD4 cell count (cells/ $\mu \mathrm{l}$, median, IQR ${ }^{\mathrm{a}}$ ) & $50(17-118)$ \\
\hline Carrying HLA B*35:05 (Number, \%) & $18(2.0)$ \\
\hline Carrying HLA B*40:01 (Number, \%) & $168(18.5)$ \\
\hline
\end{tabular}

${ }^{\mathrm{a}} \mathrm{QR}$, interquartile range.

${ }^{\mathrm{b}} \mathrm{DDU}$, intravenous drug use.

and hepato-toxicity (11.9\%) were the most represented adverse effects. Peripheral neuropathy was not the main reason for regimen modification (data not shown). The median days to regimen modification due to lipodystrophy was longest while rash-related regimen modification occurred earliest. Figure 2 shows the Kaplan-Meier estimates of regimen modification by reasons for the modification; lipodystrophy, rash and treatment failure. Lipodystrophy-related regimen modification was detected

Table 2 Reasons for regimen modification $(n=377)$

\begin{tabular}{lll}
\hline Reasons & Number (\%) & $\begin{array}{l}\text { Days to regimen } \\
\text { modification } \\
\text { (Median, IQR }\end{array}$ \\
\hline Adverse effects & $277(73.5)$ & $29(5-55)$ \\
Lipodystrophy & $175(63.2)$ & $1493(936-1946)$ \\
Rash & $49(17.7)$ & $29(24-44)$ \\
Hepatitis/Liver dysfunction & $33(11.9)$ & $146(56-315)$ \\
Lactic acidosis & $9(3.3)$ & $511(410-573)$ \\
Neuropathy & $8(2.9)$ & $506(286-574)$ \\
Others & $3(1.1)$ & $545(388-1769)$ \\
Treatment failure & $63(16.7)$ & $1147(344-1246)$ \\
For TB ${ }^{b}$ treatment & $16(4.2)$ & $186(93-248)$ \\
Pregnancy & $10(2.7)$ & $868(682-1643)$ \\
Others & $2(0.5)$ & $527(62-992)$ \\
Unknown & $9(2.4)$ & $1085(527-1705)$ \\
\hline
\end{tabular}

${ }^{\mathrm{a}} \mathrm{QQR}$, interquartile range.

${ }^{\mathrm{b}} \mathrm{TB}$, tuberculosis.

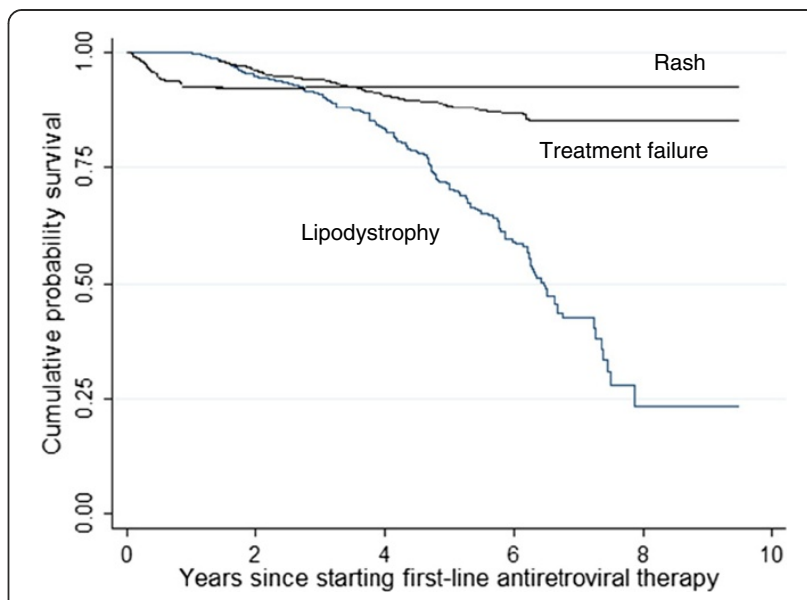

Figure 2 Kaplan-Meier curve of regimen modification stratified by reasons.

almost throughout the observation period, but rashrelated regimen modification was seen only in the first one year.

\section{Predictors of regimen modification}

As we assumed that predictors were different depending on reasons for regimen modification, we fitted Cox's proportional hazard models to elucidate冈the factors associated with reason-specific regimen modification. Covariates included in multivariable models were: gender, age, clinical status, CD4 cell count at the baseline and selected HLA-B allele. Factors independently associated with regimen modification due to lipodystrophy was being female [adjusted hazard ratio (aHR) 2.11, 95\% confidence interval (95\% CI) 1.51-2.95, p-value $<0.001]$. Age of over 35 was also weakly associated with lipodystrophy-related regimen modification (aHR 1.35, 95\% CI 0.98-1.84, pvalue $=0.06$ ) whereas there was no association between HLA-B*40:01 (Table 3) and lipodystrophy-related modification. Females had a higher hazard of rash-related regimen modification (aHR 1.82, 95\% CI 0.99-3.34, p-value = 0.05). Intriguingly HLA-B*35:05 was by far the strongest risk of regimen modification due to rash. Among 890 patients who do not have HLA-B*35:05, forty two $(4.7 \%)$ modified the regimen due to rash, whereas 6 (33.3\%) of 18 patients with HLA-B*35:05 developed a rash resulting in the regimen modification corresponding to aHR of 7.73 (95\% CI 3.16-18.9, p-value <0.001) (Table 4). CD4 cell count and clinical status at the initiation of ART did not show any association with regimen modification due to these adverse effects. None of demographic, clinical and genetic factors were associated with regimen modification due to hepatotoxicity (data not shown). Female (aHR 0.54, 95\% CI 0.30-0.96, p-value $=0.04$ ) and elder age (aHR 0.56, 95\% CI 0.32-0.99, p-value $=0.05$ ) were associated with a decreased hazard of treatment failure-related regimen 
Table 3 Predictors of regimen modification due to lipodystrophy

\begin{tabular}{lllll}
\hline & $\mathbf{H R}^{\mathbf{a}}\left(\mathbf{9 5 \%} \mathbf{C l}^{\mathbf{b}}\right)$ & $\boldsymbol{P}$ & $\mathbf{a H R}^{\mathbf{c}}\left(\mathbf{9 5 \%} \mathbf{C l}^{\mathbf{b}}\right)$ & $\boldsymbol{P}$ \\
\hline Gender & & & 1 & \\
Male & 1 & & 1 & \\
Female & $2.05(1.50-2.79)$ & $<0.001$ & $2.11(1.51-2.95)$ & $<0.001$ \\
Age & & & & \\
$<35$ & 1 & & 1 & \\
$\geq 35$ & $1.12(0.83-1.51)$ & 0.46 & $1.35(0.98-1.84)$ & 0.06 \\
Clinical status & & & & \\
Asymptomatic & 1 & & 1 & \\
Symptomatic & $0.88(0.54-1.45)$ & 0.62 & $0.81(0.48-1.36)$ & 0.43 \\
AlDS & $0.65(0.41-1.03)$ & 0.07 & $0.72(0.43-1.21)$ & 0.21 \\
CD4 cell count & & & & \\
$>$ 200 & 1 & & 1 & \\
50-199 & $0.85(0.46-1.57)$ & 0.61 & $0.95(0.50-1.80)$ & 0.87 \\
$<50$ & $0.80(0.43-1.46)$ & 0.46 & $1.08(0.56-2.07)$ & 0.83 \\
HLA-B 40:01 & & & & \\
No & 1 & & 1 & 0.62 \\
Yes & $0.92(0.64-1.32)$ & 0.64 & $0.91(0.62-1.32)$ & \\
\hline
\end{tabular}

aHR, hazard ratio.

${ }^{\mathrm{b}} \mathrm{Cl}$, confidence interval.

caHR, adjusted hazard ratio.

modification. Interestingly, the association with HLA $B^{*} 40: 01$ remained significant after adjusting other factors; those who has HLA-B*40:01 showed over 70\% lower hazard of treatment failure-related modification than that of those without HLA-B*40:01 (aHR 0.29, 95\% CI 0.10-0.82, $\mathrm{p}$-value $=0.02)($ Table 5).

\section{Discussion}

Since the choices of salvage regimen are still limited in most of low- and middle-income countries, well-managed first line ART is essential. Repeated investigation of the incidence of regimen modification and its determinants will help to keep patients on the first ART regimen as long as possible.

In the current study, 377 (41.4\%) of HIV-infected patients experienced regimen modification from the first line regimen using GPOvir ${ }^{\oplus}$ over the observation period. This proportion is similar to that reported from previous studies $[5,7,8,15]$. The incidence rate of regimen modification of 13.8/100 PYO (95\% CI:12.5-15.3) was lower than that of 22.3/100 PYO reported in the previously published multicentre study in Southeast Asia [5]. This difference might reflect the differences in the availability of salvage regimen and definition of regimen change among countries. Consistent with other studies, adverse effects, especially lipodystrophy and rash, were the represented reasons for the ART regimen modification in the present study $[5,7,20,21]$. Frequency and distribution
Table 4 Predictors of regimen modification due to rash

\begin{tabular}{|c|c|c|c|c|}
\hline & $\mathrm{HR}^{\mathrm{a}}\left(95 \% \mathrm{Cl}^{\mathrm{b}}\right)$ & $P$ & $\operatorname{aHR}^{c}\left(95 \% \mathrm{Cl}^{\mathrm{b}}\right)$ & $P$ \\
\hline \multicolumn{5}{|l|}{ Gender } \\
\hline Male & 1 & & 1 & \\
\hline Female & $1.83(1.03-3.27)$ & 0.04 & $1.82(0.99-3.34)$ & 0.05 \\
\hline \multicolumn{5}{|l|}{ Age } \\
\hline$<35$ & 1 & & 1 & \\
\hline$\geq 35$ & $1.20(0.69-2.10)$ & 0.51 & $1.08(0.60-1.93)$ & 0.81 \\
\hline \multicolumn{5}{|l|}{ Clinical status } \\
\hline Asymptomatic & 1 & & 1 & \\
\hline Symptomatic & $0.45(0.19-1.09)$ & 0.08 & $0.52(0.21-1.28)$ & 0.15 \\
\hline AIDS & $0.61(0.31-1.22)$ & 0.16 & $0.94(0.44-2.03)$ & 0.88 \\
\hline \multicolumn{5}{|l|}{ CD4 cell count } \\
\hline$>200$ & 1 & 0.75 & 1 & 0.60 \\
\hline 50-199 & $1.21(0.37-3.98)$ & & $1.38(0.41-4.63)$ & \\
\hline$<50$ & $0.70(0.21-2.39)$ & 0.58 & $0.71(0.20-2.55)$ & 0.60 \\
\hline \multicolumn{5}{|l|}{ HLA-B*35:05 } \\
\hline No & 1 & & 1 & \\
\hline Yes & $8.24(3.51-19.4)$ & $<0.001$ & $7.73(3.16-18.9)$ & $<0.001$ \\
\hline \multicolumn{5}{|l|}{ HLA-B*57:01 } \\
\hline No & 1 & & 1 & \\
\hline Yes & $1.70(0.23-12.3)$ & 0.60 & $2.06(0.28-15.4)$ & 0.48 \\
\hline
\end{tabular}

${ }^{\mathrm{a}} \mathrm{HR}$, hazard ratio.

${ }^{\mathrm{b}} \mathrm{Cl}$, confidence interval.

caHR, adjusted hazard ratio.

Table 5 Predictors of regimen modification due to treatment failure

\begin{tabular}{lllll}
\hline & $\mathbf{H R}^{\mathbf{a}}\left(\mathbf{9 5} \% \mathbf{C l}^{\mathbf{b}}\right)$ & $\boldsymbol{P}$ & $\mathbf{a H R}^{\mathbf{c}}\left(\mathbf{9 5} \% \mathrm{Cl}^{\mathbf{b}}\right)$ & $\boldsymbol{P}$ \\
\hline Gender & & & 1 & \\
Male & 1 & & & \\
Female & $0.61(0.36-1.01)$ & 0.06 & $0.54(0.30-0.96)$ & 0.04 \\
Age & 1 & & 1 & \\
$<35$ & & & & \\
$\geq 35$ & $0.54(0.32-0.92)$ & 0.02 & $0.56(0.32-0.99)$ & 0.05 \\
Clinical status & & & & \\
Asymptomatic & 1 & & 1 & \\
Symptomatic & $1.29(0.51-3.23)$ & 0.59 & $1.19(0.47-3.00)$ & 0.72 \\
AlDS & $0.92(0.39-2.20)$ & 0.86 & $0.73(0.29-1.85)$ & 0.51 \\
CD4 cell count & & & & \\
$>$ 200 & 1 & & 1 & \\
50-199 & $0.74(0.28-1.94)$ & 0.55 & $0.59(0.22-1.55)$ & 0.28 \\
$<50$ & $0.82(0.32-1.12)$ & 0.68 & $0.68(0.25-1.86)$ & 0.45 \\
HLA-B*40:01 & & & & \\
No & 1 & & 1 & 0.02 \\
Yes & $0.38(0.16-0.87)$ & 0.02 & $0.29(0.10-0.82)$ & \\
\hline
\end{tabular}

${ }^{\mathrm{a}} \mathrm{HR}$, hazard ratio.

${ }^{\mathrm{b}} \mathrm{Cl}$, confidence interval.

$\mathrm{C}_{\mathrm{aHR}}$, adjusted hazard ratio. 
of adverse effects as the reasons for the regimen modification were almost similar to those in other studies in Asia [5,22].

Predictors of the specific cause of regimen modification varied. From the risk factor analysis for each cause of regimen modification, female patients had two times higher risk of regimen modification due to lipodystrophy. Some studies reported that female gender was a risk factor for development of lipodystrophy [23,24], but it is difficult to know whether the regimen change due to lipodystrophy was related to the gender difference in this biological mechanism or simply because female were more conscious about the change in body composition for cosmetic reasons. Similar to previous studies, older age was also increased the risk of lipodystrophy-related regimen modification [23,24]. In a small case-control study in Thailand, Wangsomboonsiri et al. found the strong association between HLA-B*40:01 and development of stavudine-associated lipodystrophy [13]. Their definition of lipodystrophy was based on the strict clinical measurements, whereas we focused on the documented lipodystrophy which was severe enough to induce regimen modification. No association in our study might be due to differences in the definition of outcome.

This is the first study demonstrating that HLA-B*35:05 strongly associated with rash-related regimen modification in a longitudinal observation. A small case-control study reported that HLA-B*35:05 allele was observed in 18\% of patients with NVP-induced rash and only in $1 \%$ of those who were NVP tolerant in Thailand. They presented an increased risk of rash among those who had HLA-B*35:05 $(\mathrm{aOR} 49.2,95 \% \mathrm{CI} 6.5-374.4$, p-value $=0.0002)$ [14]. In our study, the frequency of HLA-B*35:05 among those who experienced rash-related regimen modification was slightly lower than that in previous study investigated all rash regardless of regimen modification. This discrepancy could be explained by the difference in the outcome measurement. Also, the lead-in dosing of NVP for all our participants might have played some role to reduce the risk of NVP-related rash. Unlike a single HLA class I allele of B*57:01 related abacavir hypersensitivity, different class I and class II associations have been found with NVP rash, hypersensitivity, and hepatitis [25]. Regional differences in class I HLA association are noted [26-30], partly because of the difference in HLA allele frequency distribution. As observed association between HLA-B*35:05 and regimen modification due to rash was strong, we believe that screening HLA-B*35:05 will reduce rash-induced regimen modification and related cost, especially in the region where the frequency of HLA-B*35:05 is high.

Regimen modification due to treatment failure has a different mechanism. One of the most important factors to be considered is adherence. We did not collect this kind of information since it was out of the scope of this study. However, our result that male and younger age as risk factors of regimen modification due to treatment failure is consistent with the results of our previous study with respect to adherence, treatment failure and its predictors [31]. Of note, our study showed the protective effect of HLA-B*40:01 on regimen modification due to treatment failure. Accumulating data of HLA class I alleles has been described as affecting the evolution of the HIV-sequence on both individual and population levels [32-36]. HLA-driven immune pressure may delay development of critical drug resistance mutations and lead to a better treatment outcome in some patients. To date HLA-B*40:01-associated mutation has not been described as drug resistance mutations. Although lack of information with respect to mutation and other qualitative data, our results might explain the association between HLA-B*40:01 and treatment efficacy. Another point to be carefully considered is that the incidence of treatment failure-related regimen modification might be underestimated in our study. Since we focused on the first regimen modification, those who experienced side effects-related modification before treatment failure were not included in the population at risk of treatment failure-related modification.

In this study, time to regimen modification due to lipodystrophy was around three times longer than other studies $[5,6]$. It might reflect the time lag between the diagnosis of lipodystrophy and regimen modification. Compared with other adverse effects and treatment failure, the timing of lipodystrophy-related regimen modification was decided based on more subjective reasons such as patients' preference and perception toward the appearance change rather than clinicians' decision. In our experience, some patients are reluctant to change the regimen in fear of new adverse effects or less efficacy. Among patients using the regimen of $\mathrm{d} 4 \mathrm{~T} / 3 \mathrm{TC} /$ NVP, lipodystrophy is mainly due to d4T. Since around 2008, according to the strong recommendation from WHO, zidovudine has been substituted for d4T. In Thailand, national guideline was revised and generic combination tablet of AZT/3TC/NVP (GPO-Z $)$ has been recommended as the main first-line ARV since October 2008 [18]. However, as the combination of $d 4 \mathrm{~T} / 3 \mathrm{TC} / \mathrm{NVP}$ is still one of the most commonly used first-line regimen in resource limited settings, our findings will be beneficial for clinicians in these settings to identify patients at the risk of regimen modification.

Our study has several limitations. Firstly, we could not identify the specific drug which was responsible for B*35:05 associated rash, though previous data indicates that NVP is most likely. Secondly, regimen modification may have been underestimated, especially because regimen modification due to lipodystrophy took longer time than other studies. However, we believe that our data 
reflects more the real situation in the government sector. Thirdly, we do not have detailed clinical information at the initiation of ART such as body mass index, haemoglobin level and viral load, since this study was prospective observational study and the data collection was not specifically designed for identifying the factors associating with regimen modification. Some studies reported that these factors increased the risk of early mortality [37] (maybe without regimen modification) and some adverse effects [8]. It also may lead to underestimation of regimen modification.

\section{Conclusions}

In conclusion, we present a moderate incidence rate of regimen modification from a clinical setting in northern Thailand. Adverse effects were the main reasons for regimen modification. Female gender and older age appeared to be risk factors of regimen modification due to lipodystrophy. Individuals with HLA-B*35:05 more likely to experience rash-related regimen modification. Male and younger age increased the risk of treatment failurerelated regimen modification, while female gender, older age and having HLA-B*40:01 showed protective effects.

Our findings have several implications for the better management of HIV-infected individuals on ART. Screening for HLA-B*35:05 will reduce the risk of rash-related regimen modification while HLA-B*4001 could be a predictor for durability of the combination of $\mathrm{d} 4 \mathrm{~T} / 3 \mathrm{TC} / \mathrm{NVP}$. Finally, to reduce lipodystrophy-related regimen modification, accelerated implementation of WHO recommendation for phasing-off $\mathrm{d} 4 \mathrm{~T}$ will be crucial.

\section{Additional file}

Additional file 1: Table S1. Frequency of HLA-B allele ( $n=908)$.

\section{Competing interests}

The authors declare that they have no competing interests.

\section{Authors' contribution}

KA and NT contributed to study design, interpretation of data and writing. NT contributed to data collection and data analyses. PP contributed to clinical management of patients. NW contributed to HLA genotyping and interpretation of testing. AR, WA and PS involved in conception of study design and critical review of the manuscript. All authors reviewed the manuscript during preparation and approved the final manuscript.

\section{Acknowledgements}

This study was supported by Japan International Co-operation Agency (JICA), Japan Health Science Foundation, and the Department of Medical Sciences of Ministry of Public Health of Thailand and partially by Global COE programme, Nagasaki University.

In this study, PP, NT and KA conceived the study and designed the study protocol; AR and PP carried out the clinical assessment and management; PS and WA helped with organization and execution of the study; NT contributed to data collection; NW carried out the HLA genotyping; NT and KA analyzed and interpreted the data; NT, PP and KA drafted the manuscript; All authors read and approved the final manuscript. KA is guarantor of the paper.
We would like to thank all the patients and staff at Lampang Hospital especially Ms. S Kasemsuk, Ms. S Seneewong-naayudhaya, Ms. A Suyasarojna, Mr. P Wongnamnong and Ms. K Yoddumnern, Ms. K Lor-yont, Mr. W Khaewkarnka, Mr. S Umnajsirisuk and Mr. S Niyom-thai.

\section{Author details}

${ }^{1}$ Department of Clinical Medicine, Institute of Tropical Medicine, Nagasaki University, 1-12-4, Sakamoto, Nagasaki 852-8523, Japan. ${ }^{2}$ Global COE program, Nagasaki University, 1-12-4, Sakamoto, Nagasaki 852-8523, Japan. ${ }^{3}$ Day Care Center, Lampang Hospital, 280 Paholyothin Road, Muang Lampang, Lampang 52000, Thailand. ${ }^{4}$ National Institute of Health, Ministry of Public Health, 88/7 Tiwanon road, Ampur Muang, Nonthaburi 11000, Thailand. ${ }^{5}$ Food and Drug Administration, Ministry of Public Health, 88/7 Tiwanon road, Ampur Muang, Nonthaburi 11000, Thailand.

Received: 30 July 2014 Accepted: 16 October 2014

Published online: 30 October 2014

\section{References}

1. Palella FJ Jr, Baker RK, Moorman AC, Chmiel JS, Wood KC, Brooks JT, Holmberg SD, HIV Outpatient Study (HOPS) Investigators: Mortality in the highly active antiretroviral therapy era: changing causes of death and disease in the HIV outpatient study. J Acquir Immune Defic Syndr 2006, 43(1):27-34

2. Chasombat S, McConnell MS, Siangphoe U, Yuktanont $P$, Jirawattanapisal T, Fox K, Thanprasertsuk S, Mock PA, Ningsanond P, Lertpiriyasuwat C, Pinyopornpanich S: National expansion of antiretroviral treatment in Thailand, 2000-2007: program scale-up and patient outcomes. J Acquir Immune Defic Syndr 2009, 50(5):506-512.

3. Pathipvanich P, Tsuchiya N, Rojanawiwat A, Schmidt WP, Auwanit W, Sawanpanyalert $P$, Ariyoshi K: Changing burden of HIV/AIDS to clinical settings in Northern Thailand over 15 years. Jpn J Infect Dis 2013, 66(5):375-378.

4. Cesar C, Shepherd BE, Krolewiecki AJ, Fink VI, Schechter M, Tuboi SH, Wolff M, Pape JW, Leger P, Padgett D, Madero JS, Gotuzzo E, Sued O, McGowan CC, Masys DR, Cahn PE, Caribbean, Central South America Network for, HIV Research Collaboration of the International Epidemiologic Databases to Evaluate AIDS Program: Rates and reasons for early change of first HAART in HIV-1-infected patients in 7 sites throughout the Caribbean and Latin America. PLoS One 2010, 5(6):e10490.

5. Zhou J, Paton NI, Ditangco R, Chen YM, Kamarulzaman A, Kumarasamy N, Lee CK, Li PC, Merati TP, Phanuphak P, Pujari S, Vibhagool A, Zhang F, Chuah J, Frost KR, Cooper DA, Law MG: Experience with the use of a firstline regimen of stavudine, lamivudine and nevirapine in patients in the TREAT Asia HIV Observational Database. HIV Med 2007, 8(1):8-16.

6. Cardoso SW, Grinsztejn B, Velasque L, Veloso VG, Luz PM, Friedman RK, Morgado M, Ribeiro SR, Moreira Rl, Keruly J, Moore RD: Incidence of modifying or discontinuing first HAART regimen and its determinants in a cohort of HIV-infected patients from Rio de Janeiro, Brazil. AIDS Res Hum Retroviruses 2010, 26(8):865-874.

7. Kumarasamy N, Vallabhaneni S, Cecelia AJ, Yepthomi T, Balakrishnan P, Saghayam S, Flanigan TP, Carpenter CC, Solomon S, Mayer KH: Reasons for modification of generic highly active antiretroviral therapeutic regimens among patients in southern India. J Acquir Immune Defic Syndr 2006, 41(1):53-58

8. Prosperi MC, Fabbiani M, Fanti I, Zaccarelli M, Colafigli M, Mondi A, D'Avino A, Borghetti A, Cauda R, Di Giambenedetto S: Predictors of first-line antiretroviral therapy discontinuation due to drug-related adverse events in HIV-infected patients: a retrospective cohort study. BMC Infect Dis 2012, $12: 296$.

9. Cicconi P, Cozzi-Lepri A, Castagna A, Trecarichi EM, Antinori A, Gatti F, Cassola G, Sighinolfi L, Castelli P, d'Arminio Monforte A, ICoNA Foundation Study Group: Insights into reasons for discontinuation according to year of starting first regimen of highly active antiretroviral therapy in a cohort of antiretroviral-naive patients. HIV Med 2010, 11(2):104-113.

10. Ananworanich J, Moor Z, Siangphoe U, Chan J, Cardiello P, Duncombe C, Phanuphak P, Ruxrungtham K, Lange J, Cooper DA: Incidence and risk factors for rash in Thai patients randomized to regimens with nevirapine, efavirenz or both drugs. AIDS 2005, 19(2):185-192.

11. Martinez E, Blanco JL, Arnaiz JA, Perez-Cuevas JB, Mocroft A, Cruceta A, Marcos MA, Milinkovic A, Garcia-Viejo MA, Mallolas J, Carne X, Phillips A, 
Gatell JM: Hepatotoxicity in HIV-1-infected patients receiving nevirapinecontaining antiretroviral therapy. AIDS 2001, 15(10):1261-1268.

12. Mallal S, Phillips E, Carosi G, Molina JM, Workman C, Tomazic J, JagelGuedes E, Rugina S, Kozyrev O, Cid JF, Hay P, Nolan D, Hughes S, Hughes A, Ryan S, Fitch N, Thorborn D, Benbow A, for the PREDICT-1 Study Team: HLA-B*5701 screening for hypersensitivity to abacavir. N Engl J Med 2008, 358(6):568-579.

13. Wangsomboonsiri W, Mahasirimongkol S, Chantarangsu S, Kiertiburanakul S, Charoenyingwattana A, Komindr S, Thongnak C, Mushiroda T, Nakamura Y, Chantratita W, Sungkanuparph S: Association between HLA-B*4001 and lipodystrophy among HIV-infected patients from Thailand who received a stavudine-containing antiretroviral regimen. Clin Infect Dis 2010, 50(4):597-604

14. Chantarangsu S, Mushiroda T, Mahasirimongkol S, Kiertiburanakul S, Sungkanuparph S, Manosuthi W, Tantisiriwat W, Charoenyingwattana A, Sura T, Chantratita W, Nakamura Y: HLA-B*3505 allele is a strong predictor for nevirapine-induced skin adverse drug reactions in HIV-infected Thai patients. Pharmacogenet Genomics 2009, 19(2):139-146.

15. Kiguba R, Byakika-Tusiime J, Karamagi C, Ssali F, Mugyenyi P, Katabira E: Discontinuation and modification of highly active antiretroviral therapy in HIV-infected Ugandans: prevalence and associated factors. J Acquir Immune Defic Syndr 2007, 45(2):218-223.

16. Tsuchiya N, Pathipvanich P, Rojanawiwat A, Wichukchinda N, Koga I, Koga M, Auwanit W, Kilgore PE, Ariyoshi K, Sawanpanyalert P: Chronic hepatitis B and C co-infection increased all-cause mortality in HAART-naive HIV patients in northern Thailand. Epidemiol Infect 2013, 141(9):1840-1848.

17. World Health Organization (WHO): Scaling up Antiretroviral Therapy in Resource-Limited Settings; 2002.

18. Sungkanuparph $\mathrm{S}$, Anekthananon $\mathrm{T}$, Hiransuthikul N, Bowonwatanuwong $\mathrm{C}$, Supparatpinyo K, Mootsikapun P, Chetchotisakd P, Kiertiburanakul S, Tansuphaswadikul S, Buppanharun W, Manosuthi W, Techasathit W, Ratanasuwan W, Tantisiriwat W, Suwanagool S, Leechawengwongs M, Ruxrungtham K, on behalf of the Thai AIDS Society: Guidelines for Antiretroviral Therapy in HIV-1 Infected Adults and Adolescents: The Recommendations of the Thai AIDS Society (TAS) 2008. J Med Assoc Thai 2008, 91(12):1925-1936.

19. Sungkanuparph S, Techasathit W, Utaipiboon C, Chasombat S, Bhakeecheep S, Leechawengwongs M, Ruxrungtham K, Phanuphak P, for The Adults and Adolescents Committee of the Thai National HIV Guidelines Working Group: Thai national guidelines for antiretroviral therapy in HIV-1 infected adults and adolescents. Asian Biomedicine 2010, 4(4):515-528.

20. Elzi L, Marzolini C, Furrer H, Ledergerber B, Cavassini M, Hirschel B, Vernazza P, Bernasconi E, Weber R, Battegay M, for the Swiss HIV Cohort Study: Treatment modification in human immunodeficiency virus-infected individuals starting combination antiretroviral therapy between 2005 and 2008. Arch Intern Med 2010, 170(1):57-65.

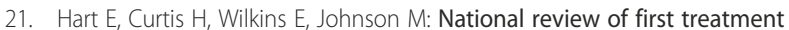
change after starting highly active antiretroviral therapy in antiretroviralnaive patients. HIV Med 2007, 8(3):186-191.

22. Pujari SN, Patel AK, Naik E, Patel KK, David A, Patel JK, Mane AA, Bhagat S: Effectiveness of generic fixed-dose combinations of highly active antiretroviral therapy for treatment of HIV infection in India. J Acquir Immune Defic Syndr 2004, 37:1566-1569.

23. Martinez E, Mocroft A, Garcia-Viejo MA, Perez-Cuevas JB, Blanco JL, Mallolas J, Bianchi L, Conget I, Blanch J, Phillips A, Gatell JM: Risk of lipodystrophy in HIV-1-infected patients treated with protease inhibitors: a prospective cohort study. Lancet 2001, 357(9256):592-598.

24. Zannou DM, Denoeud L, Lacombe K, Amoussou-Guenou D, Bashi J, Akakpo J, Gougounon A, Akonde A, Ade G, Houngbe F, Girard PM: Incidence of lipodystrophy and metabolic disorders in patients starting nonnucleoside reverse transcriptase inhibitors in Benin. Antivir Ther 2009, 14(3):371-380

25. Pavlos $R$, Phillips EJ: Individualization of antiretroviral therapy. Pharmacogenomics Pers Med 2012, 5:1-17.

26. Martin AM, Nolan D, James I, Cameron P, Keller J, Moore C, Phillips E, Christiansen FT, Mallal S: Predisposition to nevirapine hypersensitivity associated with HLA-DRB1*0101 and abrogated by low CD4 T-cell counts. AIDS 2005, 19(1):97-99

27. Phillips E, Bartlett JA, Sanne I, Lederman MM, Hinkle J, Rousseau F, Dunn D, Pavlos R, James I, Mallal SA, Haas DW: Associations between HLADRB1*0102, HLA-B*5801, and Hepatotoxicity during initiation of nevirapine-containing regimens in South Africa. J Acquir Immune Defic Syndr 2013, 62(2):e55-e57.

28. Vitezica ZG, Milpied B, Lonjou C, Borot N, Ledger TN, Lefebvre A, Hovnanian A: HLA-DRB1*01 associated with cutaneous hypersensitivity induced by nevirapine and efavirenz. AIDS 2008, 22:539-544.

29. Littera R, Carcassi C, Masala A, Piano P, Serra P, Ortu F, Corso N, Casula B, La Nasa G, Contu L, Manconi PE: HLA-dependent hypersensitivity to nevirapine in Sardinian HIV patients. AIDS 2006, 20(12):1621-1626.

30. Gatanaga H, Yazaki H, Tanuma J, Honda M, Genka I, Teruya K, Tachikawa N, Kikuchi Y, Oka S: HLA-Cw8 primarily associated with hypersensitivity to nevirapine. AIDS 2007, 21(2):264-265.

31. Tsuchiya N, Pathipvanich P, Yasuda T, Mukoyama Y, Rojanawiwat A, Matsubayashi T, Saeng-aroon S, Auwanit W, Matsuyama A, Sawanpanyalert P, Ariyoshi K: Demographic, socio-economic, behavioral and clinical factors predicting vilorogic failure with generic fixed-dose combination antiretroviral therapy before universal health insurance coverage in northern Thailand. Southeast Asian J Trop Med Public Health 2009, 40(1):1-12.

32. John M, Moore CB, James IR, Mallal SA: Interactive selective pressures of HLA-restricted immune responses and antiretroviral drugs on HIV-1. Antivir Ther 2005, 10:551-555.

33. Moore CB, John M, James IR, Christiansen FT, Witt CS, Mallal SA: Evidence of HIV adoptation to HLA-restricted immune responses at a population level. Science 2002, 296:1439-1443.

34. Palvis R, Phillips EJ: Individualization of antiretroviral therapy. Pharmacogenomics and Personalized Medicine 2012, 5:1-17.

35. Ahlenstiel G, Roomp K, Da“umer M, Nattermann J, Vogel M, Rockstroh KJ, Niko B, Rolf K, Hans-Dieter N, Sauerbruch T, Lengauer T, Ulrich Spengler on behalf of the Kompetenznetz HIV/AIDS: Selective pressures of HLA genotypes and antiviral therapy on human immunodeficiency virus type 1 sequence mutation at a population level. Clin Vaccine Immunol 2007 14(10):1266-1273.

36. Manosuthi W, Butler DM, Pérez-Santiago J, Poon FYA, Pillai KS, Mehta SR, Pacold ME, Richman DD, Pond SK, Smith DM: Protease polymorphisms in HIV-1 subtype CRF01_AE represent selection by antiretroviral therapy and host immune pressure. AIDS 2010, 24(3):411-416.

37. Gupta A, Nadkarni G, Yang WT, Chandrasekhar A, Gupte N, Bisson GP, Hosseinipour M, Gummadi N: Early mortality in adults initiating antiretroviral therapy (ART) in low- and middle-income countries (LMIC): a systematic review and meta-analysis. PLoS One 2011, 6(12):e28691.

\section{doi:10.1186/s12879-014-0565-5}

Cite this article as: Tsuchiya et al:: Incidence and predictors of regimen-modification from first-line antiretroviral therapy in Thailand: a cohort study. BMC Infectious Diseases 2014 14:565.

\section{Submit your next manuscript to BioMed Central and take full advantage of:}

- Convenient online submission

- Thorough peer review

- No space constraints or color figure charges

- Immediate publication on acceptance

- Inclusion in PubMed, CAS, Scopus and Google Scholar

- Research which is freely available for redistribution 